\title{
ELASTICITIES OF DEMAND FOR GASOLINE IN CANADA AND THE UNITED STATES
}

Christopher J. Nicol

Department of Economics

University of Regina

Regina, Saskatchewan

Canada S4S 0A2

econ@uregina.ca

MAY 2000 


\title{
Elasticities of Demand for Gasoline in Canada and the United States
}

\author{
by \\ Christopher J. Nicol \\ Department of Economics \\ University of Regina \\ Regina, Saskatchewan, S4S 0A2 \\ CANADA \\ Internet: Chris.Nicol@URegina.CA; \\ http://www.econ.uregina.ca/nicolc
}

May 28, 2000

The support of the Social Sciences and Humanities Research Council of Canada is gratefully acknowledged. I thank James Farley for outstanding research assistance. Any errors are my responsibility. 


\begin{abstract}
With recent increases in the world price of oil, there has been renewed interest in estimation of elasticities of demand for gasoline. In addition, the commitment under the Kyoto Protocol of 1997 to reduce greenhouse gas emissions by $6 \%$ from 1990 levels has led to a consideration of the responsiveness of fuel consumption to changes in price. Clearly, taxes on fuels will affect prices, so there is interest in the degree of demand responsiveness to such changes.

In this paper, a complete system of demand equations incorporating several features which have been found to be important determinants of demand is estimated. Canadian Family Expenditure (FAMEX) and United States Consumer Expenditure (CEX) Survey data are used, and complete systems of demand equations are estimated, including the demand for gasoline.

Because household-level data are used, elasticities can be estimated for a variety of household sub-groups. In addition, differences in responsiveness to own-price and income changes can be estimated for different regions of Canada and the United States. The capability of being able to estimate elasticities for different regions, and of estimating demand for gasoline as part of a demand system are two of the advantages of the approach used. This permits an analysis and discussion of how national level policies on taxes might have significantly different effects in specific regions. Thus, although demand is seen to be price inelastic, as reported in earlier studies, it is also true that there is variation in these elasticities across regions of Canada and the United States. However, larger differences are observed with respect to other household characteristics than region of residence. In addition, own-price and income responsiveness appear to be greater in Canada than the United States for otherwise comparable household groups.
\end{abstract}

\title{
JEL Codes: C3,D1
}

\section{Keywords:}

elasticities; gasoline demand; consumer demand; cross-country comparisons. 


\section{Introduction}

There has always been a significant amount of interest in the estimation of demand models for gasoline. These studies have often focused on demand estimation as a means of obtaining estimates of own-price and income elasticities of demand for gasoline. Dahl and Sterner (1991) recently surveyed this extensive literature, finding that stratification of studies by data and model type indicated a fairly significant degree of consensus with respect to short and long-run own-price and income elasticities. While reporting short and long-run own-price elasticities of -0.26 and -0.86 , on average, they also concluded that there was strong evidence that the long-run income elasticity of demand was greater than one, whereas the short-run income elasticity was less than one. This finding with respect to long-run income elasticity they viewed as a cause for concern, particularly in the United States, since they predicted increased demand for gasoline with continued income growth.

More recently, Schmalensee and Stoker (1999) provided evidence that these apparently high long-run income elasticities were probably due to a failure to control for numbers of drivers in households. On the basis of Schmalensee and Stoker's (1999) results, they concluded that the income elasticities which have appeared, particularly when based on crosssectional data, were $50 \%$ higher than they would be if one controlled for the number of licensed drivers. They then concluded that future growth in demand would likely be lower than was previously predicted.

Recent increases in the world price of oil has led to renewed interest in estimation of elasticities of demand for gasoline. The commitment under the Kyoto Protocol of 1997 to reduce greenhouse gas emissions by $6 \%$ from their 1990 levels has led to a re-consideration of the responsiveness of fuel consumption to changes in price. Taxes on fuels will affect their prices. However, previous evidence indicates that reductions from price (and tax) increases will likely not be large. On the other hand, different household groups, and households resident in different regions will possibly be affected differentially. Evidence on these differences was provided by Greening, Jeng, Formby and Cheng (1995) and Puller and Greening (1999), using United States Consumer Expenditure Survey (CEX) data. These authors used a similar modelling approach to Archibald and Gillingham (1980a, b), which viewed the 
demand for gasoline as a derived demand for an input to a household production model of transportation services.

Other studies adopt an approach which often estimates single demand equations for gasoline. Notwithstanding the wide array of data and models which have been used to study this problem, Espey $(1996,1998)$ finds that results are broadly similar in terms of estimated elasticities. That is, while vehicle ownership variables appear to significantly influence results, otherwise there are small differences in estimates, whether models are estimated with cross-sectional or time-series data, or as static or dynamic relationships. Also, however, it appears that United States responsiveness to changes in prices and income are typically smaller than responsiveness in other countries.

In this paper, rather than single-equation estimation of gasoline demand, such demand is modelled as one equation of a multi-equation demand system. Also, the influences of several other effects which have been found to be important determinants of demand are included. That is, the effect of household labour force participation, housing tenure status, household size and a variety of other household characteristics are taken into account. Several different household types in Canada and the United States are the basis for the study, employing Canadian Family Expenditure (FAMEX) Surveys, and United States CEX Surveys.

It is found that one does observe differences in elasticities between Canada and the United States, but these differences are not systematic by household type. That is, while elasticities might change in the same direction as family size for one household type in one country, this is not observed in the other country. In addition, it is seen that family size and housing tenure status variables have bigger effects on elasticities than region of residence, although elasticities are generally higher in Canada than the United States. With only one exception, gasoline is found to be own-price and income elastic. In the case of one Canadian household type, income elastic demand for gasoline is consistently observed in all regions of the country.

The implications of the foregoing results are that, while one might not consider it to be particularly important to construct policies designed to yield differential effects across regions, care ought to be taken with respect to differential impacts on households with otherwise different characteristics. It is often the case that households of certain types are 
particularly concentrated into low income levels. For example, renter households with more than one child. Thus any policy which places an undue burden on groups of this type would be best to be avoided, in the interests of equity.

In the remainder of the paper, Section 2 deals with the model specification and the computation of elasticities and their standard errors. Section 3 discusses the data sources and household types. Section 4 briefly discusses the demand model estimation approach, and presents estimated elasticities for various household types and regions in Canada and the United States. Section 5 summarises and concludes.

\section{Model Specification}

In a recent paper, Nicol (2000) proposed a model of household demand which incorporated several aspects which have been found to be important determinants of consumer behaviour. These features had not all been simultaneously included in a general demand model. Households were first stratified by family size and housing tenure status (an approach suggested in research by Barnes and Gillingham, 1984, and Nicol, 1989). Then, the demand functions were specified to have a rank three form, resulting in share equations quadratic in real expenditures. Evidence of the appropriateness of this specification is given in Banks, Blundell and Lewbel (1997) and Lyssiotou, Pashardes and Stengos, (1999). Labour force participation effects have also been found to be important (Browning and Meghir, 1991, and Kaiser, 1993). Other effects included were age of adults in the household, tobacco consumption, vehicle ownership and a variable to condition on goods not included directly in the demand system. This last variable resulted in conditional demand functions for the equations directly included in the demand system, and avoids the otherwise implicit assumption of excluded goods being separable from those goods included directly in the system.

To make these ideas more explicit, suppose "goods" over which consumers make spending decisions are partitioned into three types. Goods of direct interest, denoted $q$ (with their prices, $p$ ); labour force variables, $\ell$ (with their prices, $r$ ); and other goods of indirect interest, $c$ (with their prices, $p_{c}$ ). For convenience in what follows, let $P=\left[p, r, p_{c}\right]^{T}$ and $Q=[q, \ell, c]^{T}$. Also, let $z$ denote a vector of demographic or household characteristics variables.

Representing preferences by a utility function, $U_{h}[q, \ell, c]$, where $h$ indexes households with 
the same preferences, given the same set of household characteristics, $z$, the utility function can be re-written $U^{*}[q, \ell, c ; z]$. Under ideal circumstances, maximisation of $U^{*}[q, \ell, c ; z]$ subject to an appropriate budget constraint yields the unconditional demand functions for the elements of $q, \ell$ and $c$. These demand functions depend on $z$, so are specific to households of a particular type. Or, in other words, they are conditional demands, relative to the vector of household characteristics, $z$.

Alternatively, consider the households' cost function using the same notation and definitions for $Q, P$ and $z$

$$
\ln C^{*}\left[p, r, p_{c}, u ; z\right]=a\left(p, r, p_{c} ; z\right)+\frac{b\left(p, r, p_{c} ; z\right)}{\left[f(u)-g\left(p, r, p_{c} ; z\right)\right]}
$$

which can be re-arranged to yield the indirect utility function

$$
\ln V^{*}\left[p, r, p_{c}, y ; z\right]=f^{-1}\left\{\frac{b\left(p, r, p_{c} ; z\right)}{\left[\ln y-a\left(p, r, p_{c} ; z\right)\right]}+g\left(p, r, p_{c} ; z\right)\right\}
$$

This model specification is based on that in Fry and Pashardes (1992) (which is equivalent to expressions in Lewbel, 1991, and implicit in Gorman, 1981), with the inclusion here of the distinction between $q, \ell$ and $c$, and conditioning on $z$. Fry and Pashardes (1992) show that this indirect utility function yields the budget-share system

$$
w_{i}=a_{i}^{\prime}\left(p, r, p_{c} ; z\right)+\frac{b_{i}^{\prime}\left(p, r, p_{c} ; z\right)}{b\left(p, r, p_{c} ; z\right)}\left\{\ln (y)-a\left[p, r, p_{c} ; z\right]\right\}+\frac{g_{i}^{\prime}\left(p, r, p_{c} ; z\right)}{g\left(p, r, p_{c} ; z\right)}\left\{\ln (y)-a\left[p, r, p_{c} ; z\right]\right\}^{2}
$$

where $a_{i}^{\prime}\left(p, r, p_{c} ; z\right), b_{i}^{\prime}\left(p, r, p_{c} ; z\right)$ and $g_{i}^{\prime}\left(p, r, p_{c} ; z\right)$ are derivatives of $a\left(p, r, p_{c} ; z\right), b\left(p, r, p_{c} ; z\right)$ and $g\left(p, r, p_{c} ; z\right)$ with respect to $\ln p_{i}$.

The model in (3) above is a quadratic generalisation of the Almost Ideal (AI) demand system of Deaton and Muellbauer (1980). The quadratic AI (QAI) system nests the AI model, and is less restrictive than the quadratic expenditure system (QES) proposed by Howe, Pollak and Wales (1978). The most general form of the QES was presented in van Daal and Mierkes (1989). Lewbel (1991) developed a general representation for the QAI system, and this has been used in empirical applications by Banks, Blundell and Lewbel (1992 and 1997) and Fry and Pashardes (1992). One of the attractions of the QAI model is that it typically outperforms the popular AI system. Furthermore, it is a rank three system, 
which can be seen from Lewbel's (1991) definition of the rank of a demand system as the minimum number of functions, $g_{m}(\ln P, \ln Y ; z)$ for all $\ln P$ and $\ln Y$, and for which

$$
w_{i}=d_{i}^{*}[\ln P, \ln Y ; z]=\sum_{m=1}^{M} a_{m i}^{*}(\ln P ; z) g_{m}^{*}(\ln P, \ln Y ; z),
$$

where $\ln P$ is the vector of the logs of prices, including the prices of the elements of $\ell$ and $c$, and $Y$ also includes expenditures on these "goods". Note that $a_{m i}^{*}[\ln P ; z]$ and $g_{m}^{*}[\ln P, \ln Y ; z]$ in the notation of (4) are chosen to coincide with the notation for these objects in Lewbel (1991), and are not to be confused with $a\left[q, r, p_{c} ; z\right]$ and $g\left[p, r, p_{c} ; z\right]$ of (1) and (2) above.

The rationale for partitioning $Q$ into $q, \ell$ and $c$ in this application is that certain empirical counterparts of the consumers' complete demand system arising from an indirect utility function such as (2) are not estimable for several reasons. In particular, elements of $c$ could be durable goods. Data reflecting the service flows from these goods would be necessary for estimation and empirical identification of the parameters of the demand model. In general these flows differ from expenditures made on the same goods per unit time, however, and it is expenditures, not flows, which household expenditure surveys usually measure. In addition, with respect to labour force participation, household expenditure surveys have limited information on labour force participation variables, the elements of $\ell$. This suggests that it would be fruitful to focus on the estimation of demand systems conditional not only on $z$, but also on certain other variables. These variables' effects could then be taken into account in a general way, without specifying an explicit functional relationship for this behaviour. The demand relationship for goods of direct interest, $q$, can be as complex as desired. In the present context, it will therefore be of interest to determine the extent to which elasticity estimates obtained by this general model differ in important ways, relative to estimates which have previously appeared in the gasoline demand literature.

A conditional cost function, $C[p, u ; \ell, c, z]=\min _{q}[p \cdot q \mid U(q ; \ell, c, z)=u]$, can be defined relative to $\ell, c$ and $z$ as conditioning variables. The properties of such functions are discussed in Pollak (1969) and Browning (1983). The conditional, compensated demand functions, $q_{i}$ are the derivatives of $C[p, u ; \ell, c, z]$ with respect to $p_{i}$ and can be denoted $q_{i}=f_{i}[p, u ; \ell, c, z]$, $i=1, \ldots, n$. Also, let $y$ denote total expenditure on the $n$ goods, $q=\left[q_{1}, \ldots, q_{n}\right]^{T}$. Note 
that $n$ does not include goods which comprise expenditures on goods in the vector, $c$, and nor does $y$. Given this modified conditional cost function, a variation of the QAI model can be specified as follows

$$
\ln C[p, u ; \ell, c, z]=a(p ; \ell, c, z)+\frac{b(p ; \ell, c, z)}{[f(u)-g(p ; \ell, c, z)]}
$$

with associated indirect utility function

$$
\ln V[p, y ; \ell, c, z]=f^{-1}\left\{\frac{b(p ; \ell, c, z)}{[\ln (y)-a(p ; \ell, c, z)]}+g(p ; \ell, c, z)\right\}
$$

yielding the budget-share system

$$
w_{i}=a_{i}^{\prime}(p ; \ell, c, z)+\frac{b_{i}^{\prime}(p ; \ell, c, z)}{b(p ; \ell, c, z)}\{\ln (y)-a[p ; \ell, c, z]\}+\frac{g_{i}^{\prime}(p ; \ell, c, z)}{g(p ; \ell, c, z)}\{\ln (y)-a[p ; \ell, c, z]\}^{2}
$$

where $a_{i}^{\prime}(p ; \ell, c, z), b_{i}^{\prime}(p ; \ell, c, z)$ and $g_{i}^{\prime}(p ; \ell, c, z)$ are the derivatives of $a(p ; \ell, c, z), b(p ; \ell, c, z)$ and $g(p ; \ell, c, z)$ with respect to $\ln p_{i}$. To operationalise empirical implementation of $(7)$, functional forms must be specified for $a(p ; \ell, c, z), b(p ; \ell, c, z)$ and $g(p ; \ell, c, z)$. Following Fry and Pashardes (1992), and allowing for conditioning on the variables, $\ell, c$ and $z$, these functions are parameterised as follows

$$
a(p ; \ell, c, z)=\alpha_{0}+\sum_{i=1}^{n} \alpha_{i}(\ell, c, z) \ln p_{i}+\frac{1}{2} \sum_{i=1}^{n} \sum_{j=1}^{n} \gamma_{i j} \ln p_{i} \ln p_{j}
$$

which is the familiar functional form for the counterpart function $a[p]$ from the AI system, but here conditioned to depend on $\ell, c$ and $z$,

$$
b(p ; \ell, c, z)=\beta_{0} \prod_{i=1}^{n} p_{i}^{\beta_{i}(\ell, c, z)}
$$

again taking the form of $b[p]$ from the AI system, but incorporating the effects of $\ell, c$ and $z$, and

$$
g(p ; \ell, c, z)=b(p ; \ell, c, z) \cdot \lambda(p ; \ell, c, z)
$$

where

$$
\lambda(p ; \ell, c, z)=\lambda_{0}+\sum_{i} \lambda_{i}(\ell, c, z) \ln p_{i}
$$


The following linearisations of the functions $\alpha_{i}(\ell, c, z), \beta_{i}(\ell, c, z)$ and $\lambda_{i}(\ell, c, z)$ complete the specification

$$
\begin{gathered}
\alpha_{i}(\ell, c, z)=\sum_{j=1}^{n} \sum_{k=1}^{K}\left[\alpha_{j k} v_{k}\right] \\
\beta_{i}(\ell, c, z)=\sum_{j=1}^{n} \sum_{k=1}^{K}\left[\beta_{j 0}+\beta_{j k} v_{k}\right] \\
\lambda_{i}(\ell, g, z)=\lambda_{i}
\end{gathered}
$$

where the vector $\nu=\left[\nu_{1}, \ldots, \nu_{K}\right]^{T}$ is used to represent $\ell, c$ and $z$, for notational convenience. The influences of $\ell, c$ and $z$ are therefore confined to $\alpha_{i}(\ell, c, z)$ and $\beta_{i}(\ell, c, z)$. Given the above parameterisations for (8)-(14), the following budget-share system can be obtained:

$$
\begin{aligned}
w_{i}= & \sum_{k=1}^{K} \alpha_{i k} \nu_{k}+\sum_{j=}^{n} \gamma_{i j} \ln p_{j}+\left[\beta_{i 0}+\sum_{k=1}^{K} \beta_{i k} \nu_{k}\right][\ln (y)-a(p, \nu)]+ \\
& \left\{\lambda_{i}+\left[\beta_{i 0}+\sum_{k=1}^{K} \beta_{i k} \nu_{k}\right]\left[\lambda_{0}+\sum_{j=1}^{n} \lambda_{j} \ln p_{j}\right]\right\}[\ln (y)-a(p, \nu)]^{2}+\mu_{i}
\end{aligned}
$$

The random term, $\mu_{i}$, denotes a stochastic disturbance such that $\left[\mu_{1}, \ldots, \mu_{n}\right]^{T} \sim \mathrm{N}(0, \Omega)$. The covariance matrix of $\mu$ is singular, so only $n-1$ equations of the system need to be estimated, the parameters of the $n$ 'th being recoverable by the adding-up and integrability conditions indicated below. Empirical considerations relating to this stochastic specification will be discussed in Section 4.

Integrability conditions which the parameters of (15) must satisfy in order to be consistent with the indirect utility function, (6), are: $\sum_{i}^{n} \alpha_{i 1}=1, \sum_{i}^{n} \alpha_{i k}=0, k=2, \ldots K, \sum_{i}^{n} \gamma_{i j}=$ $0, \sum_{i}^{n} \beta_{i k}=0$ all $k$, and $\sum_{i}^{n} \lambda_{i}=0$, to satisfy adding up; $\sum_{j}^{n} \gamma_{i j}=0$ to satisfy homogeneity; and $\gamma_{i j}=\gamma_{j i}, \forall i \neq j$, to satisfy symmetry of substitution effects. A negativity condition is also required of the Slutsky matrix of the model, but this cannot be satisfied globally for this class of system. In the empirical application which follows, the integrability conditions are imposed (apart from negativity), since earlier work indicated that homogeneity and symmetry restrictions could not be rejected for these data (Nicol, 1995a,b).

Elasticity estimates can be calculated once the foregoing demand model has been estimated. Based on this model parameterisation, income $\left(\eta_{i}\right)$, compensated price $\left(\epsilon_{i j}^{*}\right)$ and 
uncompensated price elasticities $\left(\epsilon_{i j}\right)$ are respectively as follows (following Fry and Pashardes, 1992)

$$
\begin{aligned}
\eta_{i}= & \left\{\beta_{0}+\sum_{k}^{K} \beta_{i k} \nu_{k}+2\left[\lambda_{i}+\left(\beta_{0}+\sum_{k}^{K} \beta_{i k} \nu_{k}\right) \cdot \lambda_{0}\right]\left(\ln (y)-\alpha_{0}\right)\right\} / w_{i}+1 \\
\epsilon_{i j}^{*}= & {\left[1 / w_{i}\right]\left[\gamma_{i j}+\left(\beta_{0}+\sum_{k}^{K} \beta_{i k} \nu_{k}\right) \lambda_{j}\left(\ln (y)-\alpha_{0}\right)^{2}+w_{i}\left(\eta_{i}-1\right)\left(w_{j}-\sum_{k}^{K} \alpha_{j k} \nu_{k}\right)\right]+} \\
& w_{j}-\delta_{i j} \\
\epsilon_{i j}= & \epsilon_{i j}^{*}-w_{j} \eta_{i}
\end{aligned}
$$

where $\delta_{i j}=1$ if $i=j$ and 0 otherwise. It should be noted that these elasticity formulae take into account evaluation at normalised prices, $p=[1, \ldots, 1]^{T}$ and $y=1$, which are zero when logs of $p_{i}$ and $y$ are taken, and that evaluation further requires a value for the vector $\nu$. The vector of sample means of all households, or groups of households, can be used for this purpose.

Standard errors for these elasticities are computed using approximation methods. Thus if $h[\theta]$ is a vector of elasticities, with its elements nonlinear in $\theta$, a variance covariance estimator, $\hat{\mathrm{V}}[h(\hat{\theta})]$, can be estimated as follows

$$
\hat{\mathrm{V}}[h(\hat{\theta})]=H[\hat{\theta}]\{\hat{\mathrm{V}}[\hat{\theta}]\} H[\hat{\theta}]^{T}
$$

where $H[\theta]$ is the matrix of derivatives of the elements of $h[\theta]$ with respect to the elements of $\theta$, and $\hat{V}[\hat{\theta}]$ is a consistent estimator of the variance-covariance estimator of $V[\hat{\theta}]$.

\section{Data}

\subsection{FAMEX Data and Prices}

The Canadian expenditure data for this study were drawn from the 1969, 1974, 1978, 1982, 1984, 1986, 1990 and 1992 FAMEX survey public-use microdata files. Six household types were extracted from the eight surveys. These types were classified by three family sizes: married couples without children (0); married couples with one child (1); and with two children (2). Also, two types of housing tenure were used to further classify households: home-owner households with mortgages (MOR); and home renter (REN) households. The six 
categories were thus defined as MOR0, MOR1, MOR2, REN0, REN1 and REN2 respectively. For all household types, only those with age of head 18-65 and no self-employed members were included in the samples.

The expenditure categories included in the demand models to be estimated were sixequation systems, including: food consumed at home (F), alcoholic beverages (A), clothing $(\mathrm{C})$, gasoline $(\mathrm{G})$, other automobile operation $(\mathrm{O})$ and public transportation $(\mathrm{P})$.

All expenditures excluded from the "direct", six-equation demand system were dealt with as an aggregate conditioning goods, for each of the three demand systems. Labour force participation status of the male and female household members were included as explanatory (dummy) variables. These labour force participation variables interacted with other variables on the right hand side of the estimating equations. Additional household characteristics variables included as explanatory variables were age of head of household, tobacco consumption, immigration status and vehicle ownership. These last three variables were zero-one dummy variables.

Price data were taken from the Statistics Canada publication Consumer Prices and Price Indexes, Catalogue No. 62-010. These data reflect regional differences in prices in Canada for a variety of goods at a point in time. The prices were rebased to 1978, and normalised to unity at their mean. Further details of the price data, some of which had to be aggregated from less regionally aggregated data, are available from the author on request.

\subsection{CEX Data and Prices}

The CEX expenditure data were drawn from the 1980-81, 1982-83, and the annual, 1984-1992 Interview Survey Public-Use Tapes of the CEX for the United States. Since one reporting group within the CEX reports expenditures every month, monthly variation in price data can be used in identification of price parameters. In contrast, for the Canadian data, expenditures are reported for the entire year, on a recall basis.

Again, family size and housing tenure were used to classify households in the same manner as for the FAMEX data referred to above. For all six household types again, only those with age of head 18-65 and no self-employed members were included in these samples.

The expenditure categories based on the CEX data were chosen to be as close as possible 
to those used with the FAMEX data, referred to above, again yielding a comparable sixequation system with F, A, C, G, O and P as defined earlier.

Labour force participation effects were also included in the demand equations. The CEX data contain information on the labour force participation status of adult household members. Consequently, these effects were introduced as labour force participation dummy variables. One variable was included for each of the adult male and female household members. In addition, these dummy variables were interacted with various variables on the right hand side of the estimating equations.

Finally, age of head, tobacco consumption, an vehicle ownership variables were again included, as was a variable reflecting expenditures on goods not included directly in the system.

The price data used in this part of the study are unique, and were compiled by the author specifically for this and related projects. In brief, the United States Consumer Price Index data were used for many cities and States in the United States. These data only reflect intertemporal price variation. To incorporate a regional dimension to price effects, the American Chamber of Commerce Research Association (ACCRA) data were used, in conjunction with CPI data. Further details of these data are in Nicol (2000), and more detailed information is available from the author on request. Also, a longer more detailed version of Nicol (2000) is available as Nicol (1998) at

http://www.econ.uregina.ca/nicolc/papers/RankUS/July_98

\section{Demand System Estimation and Elasticity Results}

\subsection{Exogeneity of Explanatory Variables}

It is clear that several of the variables included in the demand model discussed in Section 2, such as tobacco consumption and vehicle ownership, are jointly determined with

expenditure shares. In addition, purchase infrequency for some expenditure categories during a quarter (for CEX data) calls into question the exogeneity of total expenditures $(y)$. The inclusion of labour force participation effects also indicates possible endogeneity of such variables. 
In all systems estimated, therefore, total expenditures, labour force participation of adult male and female household members, other expenditures $p_{c} \cdot c$, vehicle ownership and tobacco consumption were included as right-hand side variables, but were accounted for through the use of instrumental variables. Other right-hand side variables which were included but did not require instruments were age of the head of the household and prices.

In these circumstances, the additional instrumental variables required to implement estimation were: age squared of adult male and female household members; regional dummy variables; linearly independent squares and cross-products of price variables; a time trend; income after taxes and its square; income after taxes interacted with all adult age variables; personal taxes; government transfer payments; seven occupation dummy variables each for male and female adult members; and seven education dummy variables each for male and female adult members.

Given the above set of instrumental variables, estimation of the model (15) was carried out for all of the household groups and expenditure category demand systems indicated earlier. The GMM procedures in TSP, Version 4.3 were employed, allowing for heteroskedasticity of unknown form in the computation of the estimated variance-covariance matrices of these systems, where possible. Sargan (1983) or J tests of over-identifying restrictions indicated non-rejection of the over-identifying restrictions.

\subsection{Estimated Elasticities}

Complete matrices of compensated and uncompensated price elasticities and income elasticities for all goods an household types were computed based on the formulae, (16)-(18). Since the focus of this study are own-price and income elasticities, only these are presented. Complete matrices of all elasticities are available from the author on request.

As indicated earlier, elasticities are evaluated relative to particular household groups (MOR0-REN2), for either Canada or the United States. In addition, while elasticities can be based on averages of budget-shares and other relevant variables of all households of a particular type, the elasticities can also be computed based on averages of the same variables, but for households living in specific regions of either country.

The Canadian FAMEX data permit identification of households resident in five regions of 
Canada: Atlantic Provinces (1), Québec (2), Ontario (3), Prairie Provinces (4) and British Columbia (5). For United States CEX data, households are defined as residing in one of four regions: North-east (1), Mid-west (2), South (3) and West (4). In Tables 1 and 2, own-price and income elasticities for household groups MOR0-REN2 are presented for the five regions of Canada, and the four regions of the United States respectively.

Table 1 indicates that households in Canada with one child, whether home owner or renter, exhibit weaker responses to own-price changes in their demand for gasoline. Standard errors for the elasticities are below the elasticity estimates themselves. This weaker responsiveness is comprehensive across regions. In addition, while responsiveness is greater for either household type with no children or two children, responsiveness of renters is ceteris paribus, higher than for home owners.

On the other hand, with respect to income elasticities, the reverse pattern is observed for single child households in Table 1 . That is, single-child households have greater income elasticities of demand than childless or two-child households. Again, childless households' elasticities are lower than the elasticities of households with children. Only in the case of MOR1 households are elasticities greater than one observed.

Turning to the estimates in Table 2, for United States households, the first thing one notes is the poorer precision with which own-price elasticities are estimated. Of a total of twenty-four regional estimates, five have positive values, although their standard errors are sufficiently large as to indicate this is not necessarily problematic.

In contrast with the results in Table 1, it is households in MOR1 and REN1 groups which exhibit greater responsiveness of demand to own-price changes. This is true irrespective of region. Furthermore, with the exception of these two groups, it is observed that Canadian households' gasoline demand is more responsive to own-price changes than United States households. This is consistent with earlier research in general, but it is of interest to note that one does observe greater responsiveness for the MOR1 and REN1 household groups in the United States. This tends to reinforce the notion that it is important to look beyond average elasticities for all households, since households of different types can and do respond differently, even in different countries. Again, however, it is evident that regional differences 
in elasticities are smaller than differences associated with the family size and housing tenure household characteristics.

A consideration of income elasticities for the United States indicates that households with no children within tenure groups have the lowest elasticities. This is not quite in line with the Canadian results, where MOR0/MOR2 and REN0/REN2 estimates were fairly close, with MOR1 and REN2 being substantially different from the other two household sizes' elasticities. Again, it is generally the case that corresponding elasticities by household type are higher in the United States than Canada, with the exception of REN2 households. In addition, income elasticity variation across region in the United States is smaller than variation across household size or housing tenure status.

To summarise, the elasticities obtained based on estimation of gasoline demand as one equation in a system of demand equations are consistent with results obtained in earlier research. That is, it is generally seen for both countries that gasoline demand is own-price and income elastic. There is, however, variation in elasticities across regions, although the degree of variation is higher for family size and housing tenure status. Only one household type of the six considered indicates gasoline demand is income elastic, and this is seen for Canadian households. Elasticities are generally higher in Canada than the United States, which is again consistent with results reported in the literature. The advantage of this approach, however, is that it is possible to obtain elasticity estimates for any arbitrary group of households. Since the results indicate there can be substantial differences in these estimates, depending on the characteristics considered, policy-makers will likely wish to use this finer level of detail in construction of policies geared towards the modification of household gasoline consumption behaviour.

\section{Summary and Conclusions}

In this paper, a six-equation, rank three demand system was estimated which included a gasoline demand equation. The model also controlled for the non-separability of labour force participation effects, non-separability of other goods not included directly in the demand system, and the influence of a variety of household characteristics effects.

The same model was estimated, using Canadian and United States household microdata, 
for six different household groups, varying by family size and housing tenure status. The objective was to obtain gasoline demand elasticities for these different household groups, and to obtain estimates of these elasticities for different regions of the two countries.

While there have been many empirical studies which have estimated own-price and income elasticities of gasoline demand, this paper uses a demand system approach, unlike many other studies which estimate single gasoline demand equations, or a model based on household production of gasoline services. It is rare that such models can identify separate elasticities for different household groups or regions, although Greening, Jeng, Formby and Cheng (1995) and Puller and Greening (1999) have done so for the United States, with the household production type model.

It is found that gasoline demand is own-price inelastic, and income inelastic, except for one Canadian household type, which has income elastic demand for gasoline. Gasoline demand is generally more responsive to price and income changes in Canada, but this is not universally true for all household types. Also, while regional differences in elasticities are observed in both Canada and the United States, family size and housing tenure status have larger impacts on differences in elasticities across households.

Thus, while the elasticities obtained in this paper are consistent with earlier results, a unique opportunity is provided which allows for comparisons of elasticities by any household group one might select. This is a useful feature of the approach, since the impact of general policies designed to influence demand behaviour can have differential impacts on these different household groups. The outcome of these differential effects might not be desirable to the policy-maker, thus the existence of estimates of the extent to which responses to price and income changes differ is a useful additional piece of information which is available to the policy-maker.

\section{References}

American Chamber of Commerce Researchers Association, Inter-City Price Indices for the United States. Various years.

Archibald, R., and R. Gillingham (1980a), "An Analysis of the Short-Run Consumer Demand for Gasoline Using Household Survey Data." Review of Economics and Statistics, 
$62,622-628$.

Archibald, R., and R. Gillingham (1980b), "A decomposition of the Price and Income Elasticities of the Consumer Demand for Gasoline." Southern Economic Journal, 47, $1021-1031$.

Banks, J., R. Blundell and A. Lewbel (1992), “Kernel Regression, Quadratic Logarithmic Engel Curves and Welfare Measurement." Institute for Fiscal Studies Working Paper No. 92/14.

Banks, J., R. Blundell and A. Lewbel (1997), "Quadratic Engel Curves and Consumer Demand." The Review of Economics and Statistics, 79, 527-539.

Barnes, R. and R. Gillingham (1984), "Demographic Effects in Demand Analysis: Estimation of the Quadratic Expenditure System." Review of Economics and Statistics, 66, $591-601$.

Blundell, R., P. Pashardes and G. Weber (1993), "What Do We Learn About Consumer Demand Patterns From Micro Data." American Economic Review, 83, 570-597.

Browning, M. (1983), "Necessary and Sufficient Conditions for Conditional Cost Functions." Econometrica, 51, 851-856.

Browning, M. and C. Meghir (1991), "The Effects of Male and Female Labor Supply on Commodity Demands." Econometrica, 59, 925-951.

Bureau of Labor Statistics, Washington DC. Interview Survey Public-Use Tapes, Consumer Expenditure Surveys, 1980-1992.

Consumer Prices and Price Indexes, Catalogue No. 62-010, Prices Division, Statistics Canada, Ottawa, Canada.

Dahl, C. and T. Sterner (1991), “ Analysing Gasoline Demand Elasticities: A Survey." Energy Economics, 13, 203-210. 
Deaton, A. and J. Muellbauer (1980), “An Almost Ideal Demand System." American Economic Review, 70, 312-326.

Espey, M. (1996), "Explaining the Variation in Elasticity Estimates of Gasoline Demand in the United States: A Meta-Analysis." The Energy Journal, 17, 49-60.

Espey, M. (1998), “Gasoline Demand Revisited: An International Meta-Analysis of Elasticities." Energy Economics, 20, 273-295.

Fry, V. and P. Pashardes (1992), “An Almost Ideal Quadratic Logarithmic Demand System for the Analysis of Micro Data." Discussion Paper No. 25, City University of London.

Gorman, W. M. (1981), "Some Engel Curves." Essays in the Theory and Measurement of Consumer Behaviour in Honour of Richard Stone, A. Deaton, editor, Cambridge University Press.

Greening, L.A., H.T. Jeng, J.P. Formby and D.C. Cheng (1995), "Use of Region, Life-Cycle and Role Variables in the Short-Run Estimation of the Demand for Gasoline." Applied Economics, 27, 643-656.

Howe, H., R. Pollak and T. Wales (1978), “Theory and Time-Series Estimation of the Quadratic Expenditure System." Econometrica, 47, 1231-1247.

Kaiser, H. (1993), “Testing for Separability Between Commodity Demand and Labour Supply in West Germany." 18, 21-56.

Lewbel, A. (1991), "The Rank of Demand Systems: Theory and Non-parametric Estimation." Econometrica, 59, 711-730.

Lyssiotou, P., P. Pashardes and T. Stengos (1999), "Testing the Rank of Engel Curves with Endogenous Expenditure." Economics Letters, 64m 61-65.

Nicol, C.J. (1989), “Testing a Theory of Exact Aggregation.” Journal of Business and Economic Statistics, 7, 259-265. 
Nicol, C.J. (1995a) "Model Specification Issues in Consumer Demand Systems Using United States Microdata". Department of Economics Working Paper No. 56, University of Regina.

Nicol, C.J. (1995b) "Model Specification Issues in Consumer Demand "Model Specification Issues and Estimation Effects in Applied Demand Analysis Using Microdata". Department of Economics Working Paper No. 57, University of Regina.

Nicol, C.J. (1998) "The Rank and Model Specification of Demand Systems: An Empirical Analysis Using United States Microdata". Department of Economics Working Paper No. 78, University of Regina.

Nicol, C.J. (2000) "The Rank and Model Specification of Demand Systems: An Empirical Analysis Using United States Microdata". Canadian Journal of Economics, forthcoming.

Pollak, R. (1969), "Conditional Demand Functions and the Implications of Separability." Quarterly Journal of Economics, 83, 70-78.

Puller, S.L. and L.A. Greening (1999), "Household Adjustment to Gasoline Price Change: An Analysis Using 9 Years of US Survey Data." Energy Economics, 21, 37-52.

Schmalensee, R. and T.M. Stoker (1999), "Household Gasoline Demand in the United States." Econometrica, 67, 645-662.

Survey of Family Expenditures Microdata Files (1969, 1978, 1982 1984, 1986, 1990 and 1992). Family Expenditure Surveys Section, Statistics Canada, Ottawa, Canada.

van Daal, J. and A. H. Q. M. Mierkes (1989), "A Note on the Quadratic Expenditure Model." Econometrica, 57, 1439-1443. 
Table 1: Gasoline Own-Price and Income Elasticity

Estimates and Standard Errors, MOR0-REN2 Households. Estimates Based on Canadian FAMEX Data.

\begin{tabular}{|c|c|c|c|c|c|c|}
\hline \multirow[b]{2}{*}{ Region } & \multicolumn{6}{|c|}{ "Own-Price Elasticities } \\
\hline & MOR0 & MOR1 & MOR2 & RENO & REN1 & REN2 \\
\hline \multirow[t]{2}{*}{1} & -0.476 & -0.262 & -0.618 & -0.711 & -0.159 & -0.853 \\
\hline & 0.181 & 0.162 & 0.138 & 0.200 & 0.204 & 0.192 \\
\hline \multirow[t]{2}{*}{2} & -0.397 & -0.131 & -0.595 & -0.676 & -0.124 & -0.894 \\
\hline & 0.179 & 0.194 & 0.156 & 0.243 & 0.212 & 0.193 \\
\hline \multirow[t]{2}{*}{3} & -0.519 & -0.158 & -0.578 & -0.637 & 0.052 & -0.809 \\
\hline & 0.204 & 0.205 & 0.141 & 0.229 & 0.256 & 0.179 \\
\hline \multirow[t]{2}{*}{4} & -0.566 & -0.167 & -0.576 & -0.682 & -0.115 & -0.875 \\
\hline & 0.234 & 0.188 & 0.149 & 0.196 & 0.215 & 0.183 \\
\hline \multirow[t]{2}{*}{5} & -0.444 & -0.224 & -0.547 & -0.613 & -0.124 & -0.801 \\
\hline & 0.198 & 0.185 & 0.150 & 0.249 & 0.214 & 0.195 \\
\hline \multirow[t]{3}{*}{ All } & -0.466 & -0.185 & -0.580 & -0.670 & -0.103 & -0.853 \\
\hline & 0.188 & 0.186 & 0.144 & 0.221 & 0.219 & 0.187 \\
\hline & \multicolumn{6}{|c|}{ Income Elasticities } \\
\hline Region & MOR0 & MOR1 & MOR2 & RENO & REN1 & REN2 \\
\hline \multirow[t]{2}{*}{1} & 0.542 & 1.295 & 0.589 & 0.691 & 0.938 & 0.671 \\
\hline & 0.079 & 0.090 & 0.134 & 0.154 & 0.097 & 0.119 \\
\hline \multirow[t]{2}{*}{2} & 0.533 & 1.295 & 0.365 & 0.610 & 0.930 & 0.626 \\
\hline & 0.082 & 0.107 & 0.139 & 0.189 & 0.101 & 0.125 \\
\hline \multirow[t]{2}{*}{3} & 0.520 & 1.282 & 0.386 & 0.685 & 0.886 & 0.745 \\
\hline & 0.083 & 0.117 & 0.117 & 0.171 & 0.128 & 0.099 \\
\hline \multirow[t]{2}{*}{4} & 0.514 & 1.301 & 0.499 & 0.727 & 0.922 & 0.680 \\
\hline & 0.084 & 0.101 & 0.143 & 0.146 & 0.101 & 0.109 \\
\hline \multirow[t]{2}{*}{5} & 0.512 & 1.319 & 0.323 & 0.657 & 0.913 & 0.719 \\
\hline & 0.085 & 0.109 & 0.131 & 0.188 & 0.104 & 0.110 \\
\hline \multirow[t]{2}{*}{ All } & 0.523 & 1.296 & 0.443 & 0.673 & 0.922 & 0.680 \\
\hline & 0.083 & 0.097 & 0.123 & 0.167 & 0.103 & 0.112 \\
\hline
\end{tabular}


Table 2: Gasoline Own-Price and Income Elasticity Estimates and Standard Errors, MOR0-REN2 Households. Estimates Based on United States CEX Data.

\begin{tabular}{|c|c|c|c|c|c|c|}
\hline \multirow[b]{2}{*}{ Region } & \multicolumn{6}{|c|}{ Own-Price Elasticities } \\
\hline & MOR0 & MOR1 & MOR2 & RENO & REN1 & REN2 \\
\hline \multirow[t]{2}{*}{1} & 0.002 & -0.275 & -0.050 & 0.185 & -0.463 & 0.342 \\
\hline & 0.167 & 0.200 & 0.309 & 0.217 & 0.234 & 0.386 \\
\hline \multirow[t]{2}{*}{2} & -0.221 & -0.409 & 0.148 & -0.107 & -0.625 & -0.189 \\
\hline & 0.122 & 0.163 & 0.258 & 0.164 & 0.142 & 0.236 \\
\hline \multirow[t]{2}{*}{3} & -0.189 & -0.361 & 0.004 & -0.068 & -0.633 & -0.194 \\
\hline & 0.127 & 0.167 & 0.235 & 0.170 & 0.149 & 0.230 \\
\hline \multirow[t]{2}{*}{4} & -0.176 & -0.293 & -0.192 & -0.055 & -0.604 & -0.232 \\
\hline & 0.129 & 0.181 & 0.266 & 0.172 & 0.172 & 0.222 \\
\hline \multirow[t]{3}{*}{ All } & -0.162 & -0.339 & -0.028 & -0.026 & -0.598 & -0.125 \\
\hline & 0.131 & 0.174 & 0.269 & 0.181 & 0.168 & 0.253 \\
\hline & \multicolumn{6}{|c|}{ Income Elasticities } \\
\hline Region & MOR0 & MOR1 & MOR2 & REN0 & REN1 & REN2 \\
\hline \multirow[t]{2}{*}{1} & 0.266 & 0.573 & 0.527 & 0.688 & 0.827 & 0.829 \\
\hline & 0.144 & 0.112 & 0.098 & 0.125 & 0.193 & 0.362 \\
\hline \multirow[t]{2}{*}{2} & 0.275 & 0.628 & 0.542 & 0.785 & 0.796 & 0.991 \\
\hline & 0.116 & 0.100 & 0.088 & 0.101 & 0.124 & 0.215 \\
\hline \multirow[t]{2}{*}{3} & 0.356 & 0.647 & 0.559 & 0.745 & 0.840 & 0.896 \\
\hline & 0.114 & 0.095 & 0.086 & 0.096 & 0.131 & 0.213 \\
\hline \multirow[t]{2}{*}{4} & 0.263 & 0.628 & 0.596 & 0.764 & 0.875 & 0.980 \\
\hline & 0.116 & 0.103 & 0.083 & 0.101 & 0.147 & 0.200 \\
\hline \multirow[t]{2}{*}{ All } & 0.285 & 0.621 & 0.559 & 0.750 & 0.837 & 0.941 \\
\hline & 0.118 & 0.102 & 0.087 & 0.103 & 0.142 & 0.225 \\
\hline
\end{tabular}

